\title{
Predatory Potential of Spotted Ladybird Beetle, Harmonia octomaculata (Fabricius) (Coccinellidae: Coleoptera) on Lucerne aphid, Acyrthosiphon pisum (Harris) (Aphididae: Hemiptera) under Laboratory Conditions
}

\author{
N. Sheela and C.U. Shinde* \\ Department of Agricultural Entomology, N. M. College of Agriculture, \\ Navsari Agricultural University, Navsari - 396450 (Gujarat), India \\ *Corresponding author
}

\section{Keywords \\ Feeding potential, spotted ladybird beetle, Harmonia octomaculata \\ (Fabricius), Lucerne aphid, \\ Acyrthosiphon pisum (Harris) \\ Article Info \\ Accepted: \\ 13 August 2019 \\ Available Online: \\ 10 September 2019}

\section{A B S T R A C T}

Studies on predatory potential of larva and adult of $H$. octomaculata on A. pisum was carried out under laboratory conditions during January 2018 to April 2018.The results showed that the first, second, third and fourth instar larva consumed an average of $15.72 \pm 2.66,25.72 \pm 4.79,53.58 \pm 10.93$ and $88.94 \pm$ 14.79 aphids, respectively. The total larval consumption was $183.96 \pm 17.97$ aphids during its total developmental period when reared on A. pisum. The mean daily consumption of first, second, third and fourth instar larva was $12.09 \pm 3.03$, $14.11 \pm 3.36,21.61 \pm 5.60$ and $25.38 \pm 4.88$ aphids, respectively. The consumption of male and female adults of $H$. octomaculata was $1464.24 \pm 76.40$ and $1584.58 \pm 80.92$ aphids, respectively. Per day consumption of male and female adults was $53.86 \pm 3.56$ and $57.77 \pm 6.59$ aphids, respectively. The total consumption of $H$. octomaculata during entire lifespan was $1708.37 \pm 58.63$ aphids when fed on A. pisum.

\section{Introduction}

Coccinellid beetles are important predators of aphids in agricultural crops and have been used as biological control agents against a number of aphid species due to their ability to feed on a wide range of prey and these predatory beetles are voracious in nature and have a rapid numeric response thereby they have wonderful potential for utilization in biological pest control programme of aphids in various agro-ecosystem (Shinde, 2012).
Among the various cultivated crops, lucerne, Medicago sativa L. (Family: Medicago) has the highest feeding value as a commonly grown fodder crop. The aphids such as pea aphid, Acyrthiosiphon pisum (Harris), bluegreen aphid, Acyrthosiphon kondoi (Shinjii) and spotted alfalfa aphid, Therioaphis trifolii (Fab.) are severely feeding on lucerne crop and resulted in to 25 per cent of global production losses. The lucerne aphid, A. pisum is large in size compared to other aphids and green in colour with long appendages, usually 
abundant from spring to early summer and autumn (Ryalls et al., 2013). The aphid infestation reduces the quality and quantity of lucerne crop. This crop harbour different natural enemies viz., coccinellids, syrphids, chrysopids and hemipterous predators as well as hymenopterous parasitoids. Among the predator species of lucerne crop, coccinellids showed maximum preference $(47-62 \%)$ on aphids while it was 5 to 13 per cent by dipterans (Parihar and Vir, 1991). Therefore, sucking pest could be managed by incorporating the predator to sustain crop yield. The studies on the predatory potential of H. octomaculata on Lucerne aphid A. pisum would help in augmentation of this native and potent predator in the management of aphids.

\section{Materials and Methods}

The studies were conducted at PG Research Laboratory, Department of Agricultural Entomology, N.M.C.A., N.A.U., Navsari (Gujarat) at $30.41 \pm 3.18^{\circ} \mathrm{C}$ temperature and $42.80 \pm 7.64$ per cent relative humidity during January 2018 to April 2018. Predatory beetles and lucerne aphids were collected from lucerne field of Forage Research Scheme, NAU, Navsari and maintained under laboratory condition. Fifty neonate larvae were reared separately in plastic vials $(6 \times 4$ $\mathrm{cm}$ ) by providing the lucerne aphids right from the hatching to pupation. Each larval instar was provided with a counted number of aphids (nymphs and adults) to know the feeding potential. The numbers of aphids were increased as the larva entered into next instar. The number of aphids consumed by the larva in $24 \mathrm{hrs}$ was obtained by subtracting the number of aphids leftover from the total number of aphids supplied. Thus, the larval feeding potential was worked out for each instar as well as for the entire larval period.

To study the adult feeding potential, newly emerged adults of $H$. octomaculata beetles were kept separately in plastic containers $(6 \mathrm{x}$ $4 \mathrm{~cm}$ ). A set of fifty adults was provided with a counted number of aphids. Numbers of aphids consumed during $24 \mathrm{hrs}$ was obtained by subtracting the number of aphid left over from the total number of aphid supplied. The fresh new aphids were reintroduced daily during the present investigation. Thus, the feeding potential of an adult was worked out.

\section{Results and Discussion}

\section{Larva}

The grubs of $H$. octomaculata were voracious feeder and found highly active during predation.

\section{Feeding potential by first instar larva}

Freshly hatched larvae fed on the egg shell in the absence of aphids while neonate first instar larva after emergence moved in search of prey. The larva showed chewing action and consumed abdominal portion of prey by leaving the sclerotized head and legs (PlateI(A)). Sometimes cannibalism was observed in laboratory reared culture during food scarcity.

The data presented in Table- 1 indicated that the predatory capacity of $H$. octomaculata during first instar varied from 10 to 19 aphids with an average of $15.72 \pm 2.66$ aphids. The per day consumption $H$. octomaculata on $A$. pisum by predatory first instar larva of $H$. octomaculata was 9 to 18 aphids (Av. $12.09 \pm$ 3.03 aphids). The present findings on predatory potential of first instar larvae of $H$. octomaculata are partially agreed with the report of Rajan et al., (2018) who revealed that the first instar of Coccinella transversalis (Fabricious) consumed total 10 to 18 cabbage aphid, Brevicoryne brassicae (Linnaeus) aphids with an average of $15.20 \pm 2.60$ aphids and daily consumption was 4 to 6 aphids with an average of $5.30 \pm 0.67$ aphids. Patel et al., 
(2018) revealed that the first instar of Propylea sp. consumed 4 to 13 (Av. $10.16 \pm$ 1.93) A. pisum aphids. The difference in feeding potential of first instar might be due to the influence of different host insect and predators used in this experiment, adopted methodology and prevailing weather condition.

\section{Feeding potential by second instar larva}

Second instars larvae were more efficient feeder than first instar. They attack any part of the aphids but regularly fed on soft portion of abdomen. The grub holds prey rapidly by using forelegs held in a position to avoid the prey to escape and consumed whole aphids with chewing action (Plate-I(B)). More or less similar observations were made by Rajan et al., (2018). First instar cannibalism by second instar was observed in laboratory culture when scarcity of prey and when all stages were kept together in group rearing under laboratory conditions.

The data presented in Table-1 indicated that the predatory capacity of $H$. octomaculata during second instar varied from 20 to 39 aphids with an average of $25.72 \pm 4.79$ aphids. The per day consumption on $A$. pisum by predatory second instar larva was 10 to 22 (Av. 14.11 \pm 3.36 aphids). The present results are slightly deviated from the findings of Rajan et al., (2018) who noticed that second instar of $C$. transversalis consumed total 36 to 48 aphids when fed on cabbage aphids, $B$. brassicae with average of $39.50 \pm 3.81$ aphids and daily consumption was 11 to 13 aphids with average of $12.40 \pm 0.70$ aphids. Patel et al., (2018) revealed that the predatory potential of Propylea sp. second instar was 16 to 21 (Av. $26.66 \pm 7.59$ ) A. pisum aphids. The difference in the feeding potential of $H$. octomaculata with past worker might be due to the influence of different host insect, adopted methodology and weather conditions.

\section{Feeding potential by third instar larva}

Third instar consumed more aphids than second instar. Mode of feeding action and cannibalism behavior was similar as second instar (Plate-I(C)).

The data presented in Table-1indicated that the predatory potential of $H$. octomaculata during third instar varied from 37 to 81 aphids with an average of $53.58 \pm 10.93$ aphids. The per day consumption on $A$. pisum by predatory third instar larva was 14 to 33 aphids (Av. $21.61 \pm 5.60$ aphids). The present findings are deviated from the results of Rajan et al., (2018) who reported that third instar of $C$. transversalis consumed 60 to 100 cabbage aphids, B. brassicae with average of $86.30 \pm$ 13.71 aphids and daily consumption was 20 to 25 aphids with average of $23.30 \pm 1.89$ aphids. Patel et al., (2018) revealed that the feeding potential of Propylea sp. third instar was 26 to 71 (Av. $52.86 \pm 12.87$ ) aphids (A. pisum). The difference in the feeding potential of third instar larva of $H$. octomaculata might be due to influence of host insect, adopted methodology and prevailing weather condition.

\section{Feeding potential by fourth instar larva}

The fourth instars were found more voracious in nature. The feeding behavior was similar as third instar while severe cannibalism was observed by fourth instar larvae during scarcity of prey in laboratory reared culture (Plate-I(D)).

The data presented in Table-1indicated that the predatory capacity of $H$. octomaculata during fourth instar varied from 69 to 139 aphids with an average of $88.94 \pm 14.79$ aphids. The per day consumption on $A$. pisum by predatory fourth instar larva was 17.25 to 37.67 aphids (Av. $25.38 \pm 4.88$ aphids). The present findings are deviated from the results 
of Ali et al., (2017) reported that the aphids consumption by fourth larval instar Coccinella septempunctata (Lin.) was 315.00 Aphis gossypii (Glover) aphids. Rajan et al., (2018) who revealed that fourth instar larva of $C$. transversalis consumed 152-185 cabbage aphid (B. brassicae) with an average of 167.30 \pm 12.35 aphids with daily consumption was 36 to 40 aphids with average of $38.20 \pm 1.81$ aphids. Patel et al., (2018) revealed that the fourth instars of Propylea sp. consumed 62 to 83 (Av. $75.06 \pm 4.32$ ) A. pisum aphids. The report of Patel et al., (2018) supports the present findings.

\section{Total larval feeding potential}

The data presented in Table- 1 showed that the feeding rate increased gradually from the first to fourth instar. The predatory capacity of $H$. octomaculata during entire larval duration was varied from 157 to 229 aphids with an average of $183.96 \pm 17.97$ aphids. The per day consumption on $A$. pisum by predatory larva was 54.00 to 86.75 aphids (Av. $73.19 \pm 7.75$ aphids). Further, Rauf et al., (2013) revealed that the larvae of $C$. septempunctata consumed 667.8 Schizaphus graminum (Rond.) aphids at $30 \pm 1{ }^{\circ} \mathrm{C}$ temperature. Rajan et al., (2018) revealed that the fourth instar of $C$. transversalis consumed 268 to 329 aphids with average of $308.30 \pm 32.48$ aphids during its larval period. Khan et al., (2016) reported that the larva of Harmonia dimidiate (Fab.) consumed $827.7 \pm 13.39$ M. persicae aphids during larval duration under laboratory condition. The present findings are deviated from the above worker and it might be due to different coccinellid predator and prey species used in this experiment, adopted methodology and prevailing weather condition.

\section{Feeding potential by adult}

The feeding behavior of grub and adults were more or less similar. Adult attacked any body part of aphid and showed a chewing action and the whole prey was consumed (Plate$\mathrm{I}(\mathrm{E})$ ). The prey consumption of female adult was observed more than male adult during the present investigation and it might be due to requirement of food material to perform the adult maturity and reproduction activity. Egg cannibalism by adult was observed during food scarcity in laboratory reared culture.

The results obtained during the present investigation are presented in Table- 1 revealed that male beetle consumed 1231 to 1539 aphids (Av. $1464.24 \pm 76.40$ aphids) during adult period while, female beetle consumed 1332 to 1699 aphids (Av. $1584.58 \pm 80.92$ aphids). The overall data indicated that female adults lived longer and consumed more number of aphids than male adults of $H$. octomaculata. The present investigation on feeding potential of adults are deviated from the results of Khan et al., (2016) who revealed that the predatory potential of male and female of $H$. dimidiata was maximum $14183.0 \pm$ 543.76 and $15375.0 \pm 549.98$ aphids at $24 \pm$ $1{ }^{\circ} \mathrm{C}$ when fed on $M$. persicae. According to Mishra and Kanwat (2017), the female adult of C. septempunctata consumed 1899.95 aphids while, male adult consumed 1508.28 aphids during its life time when fed on $L$. erysimi. Guroo et al., (2017) reported that the male and female of $C$. septempunctata consumed $1172.8 \pm 14.99$ and $1515.3 \pm 20.56$ aphids, respectively when fed on L. erysimi.

Data pertaining to per day consumption ability of $H$. octomaculata is presented in Table- 1 indicated that the male beetle consumed 44.89 to 59.84 (Av. $53.86 \pm 3.56$ ) aphids while female beetle consumed 45.94 to 69.04 (Av. $57.77 \pm 6.59$ ) aphids when fed on A. pisum. The present findings are disagree with the report of Mishra and Kanwat (2017) who reported that the daily feeding potential of female and male of $C$. septempunctata on $L$. erysimi was $158.32 \pm 1.03$ and $125.69 \pm 3.26$ 
aphids, respectively. The deviation in the feeding potential of adult of $H$. octomaculata might be due to difference in the predator and prey species used in present study and weather condition existing in a particular locality.

Table.1 Feeding potential of larva and adult of H. octomaculata on Lucerne aphid, A. pisum

\begin{tabular}{|c|c|c|c|c|c|c|c|}
\hline \multirow[t]{2}{*}{ Stages } & \multirow{2}{*}{$\begin{array}{c}\text { No. } \\
\text { observed }\end{array}$} & \multicolumn{3}{|c|}{ Total aphids consumed } & \multicolumn{3}{|c|}{ Per day aphids consumption } \\
\hline & & Min. & Max. & Av. \pm S.D. & Min. & Max. & Av. \pm S.D. \\
\hline \multicolumn{8}{|c|}{ Larva } \\
\hline I instar & 50 & 10 & 19 & $15.72 \pm 2.66$ & 9 & 18 & $12.09 \pm 3.03$ \\
\hline II instar & 50 & 20 & 39 & $25.72 \pm 4.79$ & 10 & 22 & $14.11 \pm 3.36$ \\
\hline III instar & 50 & 37 & 81 & $53.58 \pm 10.93$ & 14 & 33 & $21.61 \pm 5.60$ \\
\hline IV instar & 50 & 69 & 139 & $88.94 \pm 14.79$ & 17.25 & 37.67 & $25.38 \pm 4.88$ \\
\hline Total consumption & 200 & 157 & 229 & $183.96 \pm 17.97$ & 54.00 & 86.75 & $73.19 \pm 7.75$ \\
\hline \multicolumn{8}{|c|}{ Adult } \\
\hline Male & 50 & 1231 & 1539 & $1464.24 \pm 76.40$ & 44.89 & 59.84 & $53.86 \pm 3.56$ \\
\hline Female & 50 & 1332 & 1699 & $1584.58 \pm 80.92$ & 45.94 & 69.04 & $57.77 \pm 6.59$ \\
\hline $\begin{array}{l}\text { Total consumption } \\
\text { during entire } \\
\text { lifespan }\end{array}$ & 300 & 1499.0 & 1791.5 & $1708.37 \pm 58.63$ & - & - & - \\
\hline
\end{tabular}

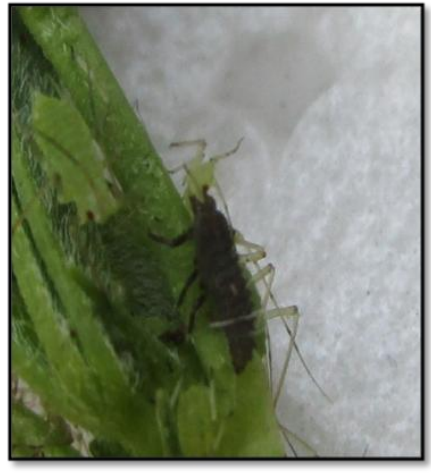

A- First instar

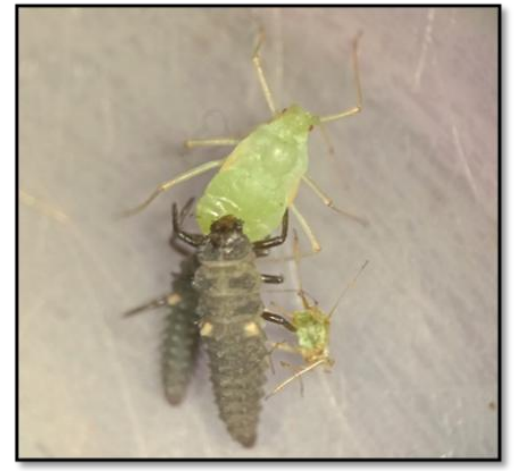

B-Second instar

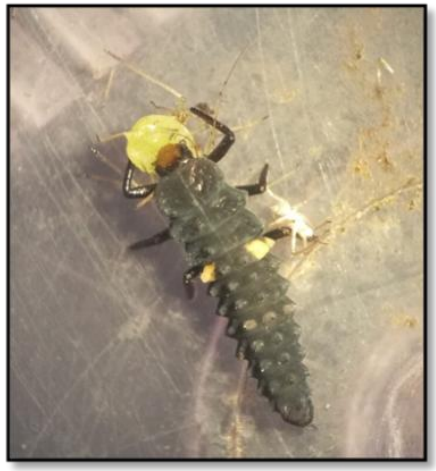

C-Third instar

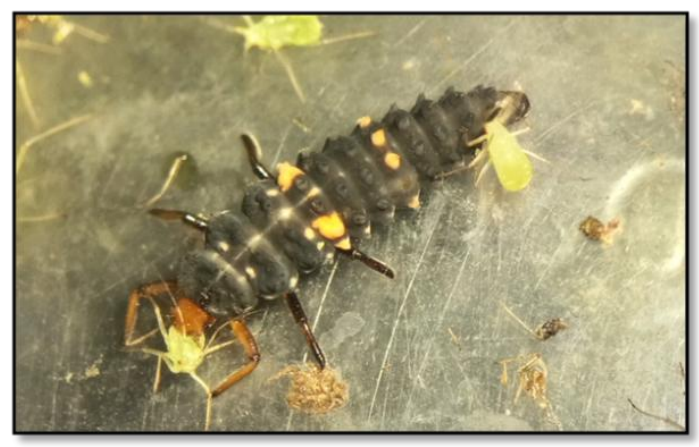

D- Fourth instar

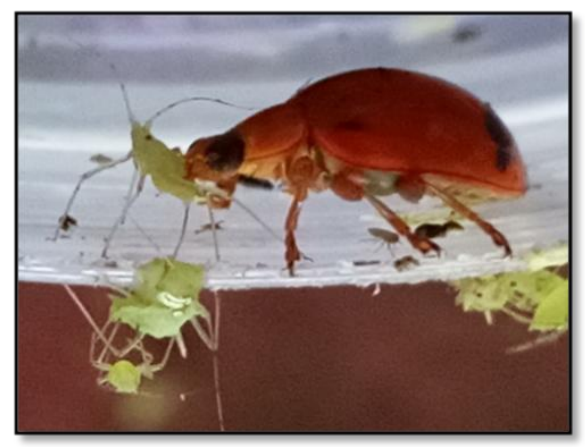

E- Adult

Plate-I: Predation of different larval stages and adult of $\mathrm{H}$. octomaculata on $\mathrm{A}$. pisum 
Total feeding potential during entire life span

The total feeding potential of $H$. octomaculata on $A$. pisum during whole lifespan is presented in Table-1and the result noted that the consumption ability varied from 1499.0 to 1791.5 aphids with an average of $1708.37 \pm$ 58.63 aphids. Earlier, Manpoog et al., (2016) who reported that the adult of $C$. septempunctata consumed $2691.00 \pm 533$ aphids (L. erysimi) during its total lifespan and daily consumption was $81.55 \pm 15.34$ aphids; $2429.83 \pm 262.28$ aphids were consumed by the adult of $C$. septempunctata when reared on L. erysimi (Yadav et al., 2016). The above findings are deviated from the present investigation and it might be due to change in predator and prey species, adopted methodology and prevailing weather conditions.

\section{Acknowledgement}

We are grateful to Director of Research and Dean Post Graduate Studies, Navsari Agricultural University, Navsari for providing necessary facilities to conduct the research. Author is also thankful to Professor and Head, Department of Entomology, N. M. College of Agriculture, Navsari Agricultural University, Navsari, for providing laboratory facilities throughout the research work.

\section{References}

Ali, A., Shafique, A.M., Mastoi, A. H., Narejo, M., Azizullah, Afzal, M. and Ahmed, S. (2017). Biology and feeding potential of Ladybird beetle (Coccinella septempunctata) against different species of aphids. Science International (Lahore), 29(6): 1261-1263.

Khan, J., Haq, E. U., Mehmood, T., Blouch, A., Rafi, M. A. and Fateh, J. (2016). Effect of temperature on the biology and predatory potential of Harmonia dimidiata (Fab.) (Coleoptera: Coccinellidae) feeding on Myzus persicae (Sulzer) (Hemiptera: Aphididae) aphid. International Journal of Environment, Agriculture and Biotechnology, 1(3): 342-349.

Guroo, M. A., Pervez, A., Srivastava, K. and Gupta, R. K. (2017). Effect of nutritious and toxic prey on food preference of a predaceous ladybird, Coccinella septempunctata (Coleoptera: Coccinellidae). European Journal of Entomology, 114: 400-406

Manpoong, N. S., Firake, D. M., Behere, G. T. and Rajesh, T. (2016). Biological attributes and feeding potential of three dominant predators of Lipaphis erysimi (Kaltenbach). Journal of Biological Control, 30(3): 190-194.

Mishra, S. K. and Kanwat, P. M. (2017). Biology and predatory potential of Coccinella septempunctata Linn. on Lipaphis erysimi Kalt. under controlled conditions. Plant Archives, 17(2): 10991104.

Parihar, D. R. and Vir, S. (1991). Insect fauna of lucerne (Medicago Sativa Linn.) crop in desert belt of rajasthan. Annals of Arid Zone, 30(3): 67-274.

Patel, A. H., Shinde, C. U. and Gurjar, T. S. (2018). Predatory potential of ladybird beetle, Propylea sp. (Coccinellidae: Coleoptera) on lucerne aphid, Acyrthosiphon pisum (Harris) (Aphididae: Hemiptera) under laboratory conditions. Journal of Entomology and Zoology Studies, 6(5): 138-140.

Rauf, M., Ehsan-ul-Haq, Khan, J., Rehman, A., Gillani, W. A. and Ali, A. (2013). Biology and predatory potential of Coccinella septempunctata Linn. on Schizaphis graminum aphid under controlled conditions Pakistan Journal of Agriculture, 26(2): 124-129. 
Rajan, J. S., Sree Latha, E., Raghavendra, R. V. and Rao, C. H. R. (2018). Biology and feeding potential of Coccinella transversalis (Fab.) on cabbage aphid, Brevicoryne brassicae (Linn.) Journal of Entomology and Zoology Studies, 6(6): 51-56.

Ryalls, J.M.W., Riegler, M., Moore, B. D. and Johnson, S. N. (2013). Biology and trophic interactions of lucerne aphids. Agricultural and Forest Entomology, 15: 335-350.

Shinde, C. U. (2012). Bio-ecology and utilization of predatory coccinellids for the management of aphids under South Gujarat condition. Ph.D. Thesis, submitted to Navsari Agricultural University, Navsari.

Yadav, M. K., Patel, J. I. and Pareek, A. (2016). Biology and predatory potential of ladybird beetle, Coccinella septempunctata (Lin.) on mustard aphid, Lipaphis erysimi (Kalt). Indian Ecological Society: International Conference, Pp: 723-724.

\section{How to cite this article:}

Sheela, N. and Shinde, C.U. 2019. Predatory Potential of Spotted Ladybird Beetle, Harmonia octomaculata (Fabricius) (Coccinellidae: Coleoptera) on Lucerne aphid, Acyrthosiphon pisum (Harris) (Aphididae: Hemiptera) under Laboratory Conditions. Int.J.Curr.Microbiol.App.Sci. 8(09): 832-838. doi: https://doi.org/10.20546/ijcmas.2019.809.100 